\title{
Identification of Structural Changes in Labor Productivity in Russia
}

\author{
Potaptseva E.V. \\ Institute of Economics, Ural Branch of the RAS, \\ Ekaterinburg, Russia, \\ potaptseva.ev@uiec.ru
}

\author{
Smirnykh S.N. \\ Ural State University of Economics, \\ Ekaterinburg, Russia, \\ sns6@yandex.ru
}

\author{
Franz M.V \\ Ufa State Aviation Technical University, \\ Ufa, Russia, \\ tan-marina@mail.ru
}

\begin{abstract}
This article aims to study long-term changes in labor productivity in the Russian economy. The aim of the study is an empirical estimation of structural changes in labor productivity in Russia. To achieve the goal, the methods of statistical, descriptive and econometric analysis were used. The informational basis for the study was the data on labor productivity of the Organization for Economic Cooperation and Development (OECD), the Unified Archive of Economic and Sociological Data (UAESD), the International Labor Organization (ILO) and the Federal State Statistics Service of the Russian Federation. In the course of the study, the following tasks were consistently solved: firstly, methods for identifying structural changes have been systematized; secondly, empirical data, tools and research methods have been described; thirdly, the identification of structural changes in labor productivity in Russia (for the period 2003-2018) has been carried out. The results of econometric analysis showed that structural changes in labor productivity in Russia took place in the second quarter of 2008: its average annual growth rate was $5.96 \%$ in $2003-2008$ and only $0.27 \%$ in $2008-2018$. The structural changes in labor productivity is associated with the negative impact on the Russian economy of external shocks: the global financial crisis of 2008-2009 and economic sanctions imposed on Russia in 2014.
\end{abstract} Russia

Keywords-labor productivity, structural changes identification,

\section{INTRODUCTION}

Long-term changes in labor productivity are of interest to economists for several reasons. First, in the long term, labor productivity is a key factor which determines living standards and social standards, and its possible changes have a significant impact on such important aspects of socioeconomic policy as, for example, the balance of the pension system. Second, an incorrect estimation of the labor productivity dynamics can lead to serious miscalculations in socio-economic policy. So A. Orphanides proves that one of the reasons for "period of high inflation", characterized by such negative phenomena as four economic recessions, two serious energy crises and the unprecedented peacetime introduction of state control over wages and prices, to happen in the United States, is that the Federal reserve system failed to detect the decline in productivity in the early 1970s, which led to an underestimation of the American economy weakness [1].

The analytical basis for identifying long-term changes in the economic indicators dynamics is the econometrics of structural changes. This intensively developing part of econometric science is looking for methods to identify changes in the parameters of random processes, including testing methods for the presence of structural changes, determining shear moments and their confidence intervals, etc. In general, there are two approaches to modeling structural changes: the first one is to assume that the changes occur instantly at a certain point in time, the second one is based on the fact that the changes occur gradually over a certain time interval [2]. Despite the fact that the version considering a structural change occuring over a period of time, and not at once, seems more realistic, most analytical works on the topic of structural changes in labor productivity use both approaches with subsequent comparison of the results. For example, L. Benati uses both approaches to study structural changes in labor productivity in the United States, the European Union, Australia and Japan after the Second World War [3]. As a result of the study, three periods characterized by different rates of growth in labor productivity were identified in the United States:

- 1950-1960s was the "golden era" with high growth rates;

- a period of significant slowdown in growth rates from the early 1970 s to the mid-1990s;

- new acceleration since the mid-1990s. 
In the Eurozone, there has been a decrease in the growth rate of labor productivity since the early 80 s of the 20th century.

The discussion about the need to increase labor productivity and the ways and consequences of stimulating the creation of highly productive jobs in the Russian economy has remained relevant for a long time. Most of the theoretical and empirical studies in this area are devoted to cross-country comparisons and analysis of sectoral dynamics of labor productivity in Russia [4-7]. Studying the relationship between structural changes in employment and the dynamics of labor productivity in the Russian work economy was carried out by I. B. Voskoboinikov and V. E. Gimpelson [8, 9]. Interregional labor productivity differentiation is occasionally investigated, confirming the high spatial unevenness of the Russian socio-economic development [10, $11]$.

The results of the studies presented above indicate a significant gap of labor productivity in Russia with most countries of the Organization for Economic Cooperation and Development (OECD). The cumulative growth of labor productivity in Russian economy has been stated during the 1991-2018 period, but the dynamics of its change is reversible and unstable. At the same time, there are practically no empirical studies aimed at identifying structural changes in labor productivity based on data from Russia during the transformation period.

The relevance of this study is due to the need to assess the effectiveness of programs implemented by the state to increase labor productivity in the Russian Federation as well. Therefore, the presence of significant positive structural changes in labor productivity may indirectly indicate the effectiveness of the measures used to increase labor productivity.

This work is aimed at further expanding existing research on the empirical identification of structural changes in labor productivity (based on Russian data). It consistently solves the following tasks:

- methods of structural changes econometrics based on the first approach are systematized, when it is assumed that the change occurs instantly at a certain point in time;

- an empirical analysis of the level and dynamics of labor productivity in Russia in 1992-2017 is carried out;

- identification of structural changes in labor productivity based on Russian data (2003-2018) is being performed.

\section{MATERIALS AND METHODS OF RESEARCH}

Applied time series analysis is based on the assumption that the parameters of a random process are constant over time, such as mean, variance, and trend. In case that at least one of the parameters of a random process changes its value, they speak of a structural change. A structural change can occur to different parameters of a random process and have different consequences - the trend, volatility or the time series levels autocorrelation characteristics can change.
In our work, we will use the simplest time series model the first-order autocorrelation process AR (1). The formula for the AR (1) process is:

$$
y_{t}=\propto+p \cdot y_{t-1}+e_{t},
$$

where $e_{t}$ is an independent random variables with zero mean and the same variance $\sigma^{2}$.

Therefore, the considered random process has three parameters: $\propto, p, \sigma^{2}$. A structural shift is understood as a change in at least one of these parameters. In the equation above $y_{t}$ is a labor productivity growth rate, therefore, the parameters $\alpha$ and p determine the average value of the growth rate in labor productivity through the ratio $E\left(y_{t}\right)=\mu=\frac{\alpha}{1-\rho}$.

Changes in $\mu$ are changes in the labor productivity trend which are of practical interest in terms of labor productivity. In addition, changes in the parameter $\rho$ reflect changes in the time series levels autocorrelation. Changes in the $\sigma^{2}$ parameter reflect changes in the time series volatility.

This paper uses the following structural changes econometrics methods:

- testing for the presence of a structural change at a previously unknown moment in time;

- determining the change moment and its confidence interval;

- testing for a change in trend.

Let us describe the methods used in further detail.

Testing for the presence of a structural break at a previously unknown point in time

The classic test for the presence of a structural change at a particular point in time is the Chow test. The idea behind this test is to split the sample in two, estimate the parameters for each subsample and then test the hypothesis that the two sets of parameters are equal. This test has been used for many years and has been adapted to many econometric models.

However, in the Chow test, the shear point must be known in advance. Therefore, the researcher has two options - to independently arbitrarily "assign" the shear moment or to justify the shear moment, based on additional information about the time series. In the first case, the researcher runs the risk of missing the shift if he misses the moment. In the second case, the researcher runs the risk of finding a shift where it actually does not exist. Moreover, it is clear that in both cases the results will depend on the random choice of the researcher, so different researchers, when analyzing the same data, may come to different results, which hardly characterizes the method as scientific and objective.

Therefore, the shear moment should be considered unknown. The answer to the question of which value to use as a test statistic when testing for the presence of a structural change in this case was given by R. Quandt - he suggested using the largest statistic in the Chow test among all possible options [12]. However, only when the shear point is known in advance, the X2 distribution can be used to estimate statistical significance. If the shear moment is not known in advance, then the distribution of $\mathrm{X} 2$ cannot be used to obtain critical 
values. The question of how to obtain critical values in this case remained unanswered for many years, until at the beginning of the 1990s the problem was simultaneously solved by several researchers, among whom the most general result was obtained by Andrews [13] and Andrews and Ploberger [14]. These authors calculated critical values, and Hansen proposed a method for calculating p-values [15]. Note that these critical values are significantly larger than those obtained using the X2 distribution [2].

If it is possible to prove that there was one structural change, then it should be assumed that there may be more of them. Bai J. and Perron P. have proposed a method to test for multiple structural changes [16]. Their method consists in sequentially dividing the sample into two and testing each of the subsamples for a structural change presence and its moment. The process continues until the hypothesis of a structural change is rejected in each of the subsamples [2].

\section{The structural change moment assessment}

In many applications, it is important to assess the structural change moment. The most suitable option, at first glance, seems to be the moment for which the statistics in the Chow test are maximum, but this is not. The best candidate for the shear moment is the moment when the smallest residual sum of squares is achieved across the entire sample by dividing it into two subsamples and evaluating two regression models for each of the subsamples. This approach was developed by Bai and his co-authors [16-18], who succeeded in obtaining an asymptotic distribution for the shear moment and constructing a confidence interval for it [2]. These confidence intervals are very useful as they allow us to judge the estimate's accuracy.

Testing for a change in trend

Testing for a change in trend is performed using the Student's $\mathrm{t}$ test. Test statistics are calculated using the following formula (2):

$$
\mathrm{t}=\frac{\mu_{1}-\mu_{2}}{\sqrt{\operatorname{var}\left(\mu_{1}\right)+\operatorname{var}\left(\mu_{2}\right)}},
$$

In this formula $\mu_{1}$ is a point estimate of the mathematical expectation of the time series level in the first period; $\mu_{2}$ is a point estimate of the mathematical expectation of the time series level in the second period; $\operatorname{var}\left(\mu_{1}\right)$ is a variance estimate of $\mu_{1} ; \operatorname{var}\left(\mu_{2}\right)$ is a variance estimate of $\mu_{2}$.

The study empirical basis was the data from the following sources:

- Organization for Economic Cooperation and Development (OECD) in Russia for the period from 1992 to $2017^{1}$;

- Unified archive of economic and sociological data ${ }^{2}$;

1 Statistical data of the Organization for Economic Cooperation and Development posted on its website (https://data.oecd.org/ (access date 04/22/2019)). Labour productivity is calculated as GDP per hour worked. To compare the levels of labour productivity between countries, GDP in national currency and current prices is converted into a unified currency - US dollars at purchasing power parity (PPP)

${ }^{2}$ Statistical data of the Unified Archive of Economic and Sociological Data (UAESD): Real GDP Index according to OKVED (GDPEA_Q_DIRI). Real GDP Index, seasonally adjusted (GDPEA_Q_DIRI_SA). The volume of GDP in current prices according to OKVED (GDPEA C Q)
- International Labor Organization (ILO) ${ }^{3}$

- Federal State Statistics Service of the Russian Federation ${ }^{4}$.

The data, allowing to calculate the dynamics of labor productivity, were used to identify structural changes in labor productivity in the Russian Federation.

The source data includes quarterly:

- real GDP index, seasonally adjusted $(\%)^{5}$, calculated by the Central Administrative Center of the SU-HSE according to the Federal State Statistics Service as seasonal smoothing of the real GDP index using a special algorithm. The data are posted in the Unified Archive of Economic and Sociological Data (UAESD). January 2003 was taken as the base period.

- the number of employed people (thousand people), obtained by the Federal State Statistics Service ${ }^{6}$ based on the materials of the labor force sample surveys with the subsequent dissemination of the results to the entire population of the surveyed age. The data are posted on the OECD website ${ }^{7}$. This is due to the fact that quarterly data till 2018 inclusive can be found only there (on the Federal State Statistics Service website quarterly data ends in the 3rd quarter of 2013).

[Electronic resource] http://sophist.hse.ru/exes/tables/GDPEA_Q.htm (access date $04 / 23 / 2019$ )

${ }^{3}$ Statistical data of the International Labour Organization (ILO): Statistics and databases // International Labor Organization [Electronic resource]. URL: https://www.ilo.org/global/statistics-and-databases/lang-en/index.htm (date of access 04/26/2019). Labour productivity, according to the ILO method, is the amount of products produced for a certain period per worker. Calculated as GDP at constant 2010 prices divided by total employment

${ }^{4}$ The data of the Federal State Statistics Service posted on its website (http://www.gks.ru (date of access 12.04.2019)).

${ }^{5}$ Statistical data of the Unified Archive of Economic and Sociological Data (EAESD): Real GDP index according to OKVED (GDPEA_Q_DIRI). Real GDP Index, seasonally adjusted (GDPEA_Q_DIRI_SA). The volume of GDP in current prices according to OKVED (GDPEA C Q) [Electronic resource] http://sophist.hse.ru/exes/tables/GDPEA_Q.htm (access date $04 / 23 / 2019$ ).

${ }^{6}$ Sample surveys of the labor force from 1999 to August 2009 were carried out at quarterly intervals. From September 2009, the survey was transferred to a monthly frequency. The sampling units are private households; units of observation - persons aged 15 and older - members of these households (until 2017 - persons aged 15-72).

Since January 2017, about 77 thousand people have been interviewed during each survey. ( $0.06 \%$ of the population of the surveyed age). For the constituent entities of the Russian Federation, a different proportion of selection is applied, taking into account the total population and the relative variation in the "unemployment rate" indicator. The sample is formed on the basis of the primary information array of the All-Russian Population Census (VPN-2010), which contains information about the permanent population, that is, the population permanently residing in the territory of the corresponding region, city, settlement.

Employed - persons aged 15 years and older who, during the survey week, performed any activity (at least one hour per week) related to the production of goods or the provision of services for payment or profit. The number of employed also includes persons who were temporarily absent from the workplace for a short period of time and retained contact with the workplace during the absence.

For the constituent entities of the Russian Federation, in order to increase the representativeness of the data, monthly survey data were formed on average for 3 months using a set of three consecutive samples. Annual data were generated on average for 12 months over a set of twelve consecutive samples.

Tourism receipts and spending. International receipts, US dollars, 2008 2017 // OESD Data [Electronic resource]. URL: https://data.oecd.org/ (access date 07.05.2018.) 
All indicators are taken from the 1st quarter of 2003 to the 4th quarter of 2018 (64 observations, quarterly data).

The changes dynamics in the studied indicators is shown in Fig. 1 and 2.

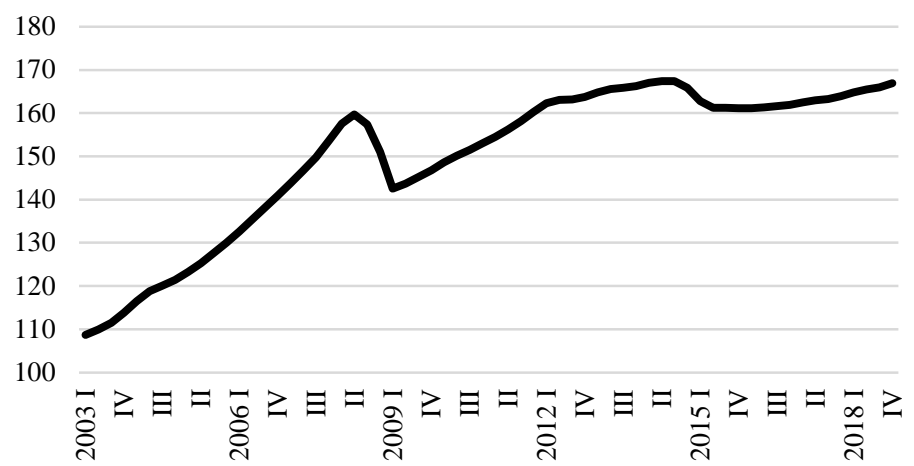

Fig. 1. The real GDP index dynamics in the Russian Federation, seasonally adjusted (in $\%$ to the base period)

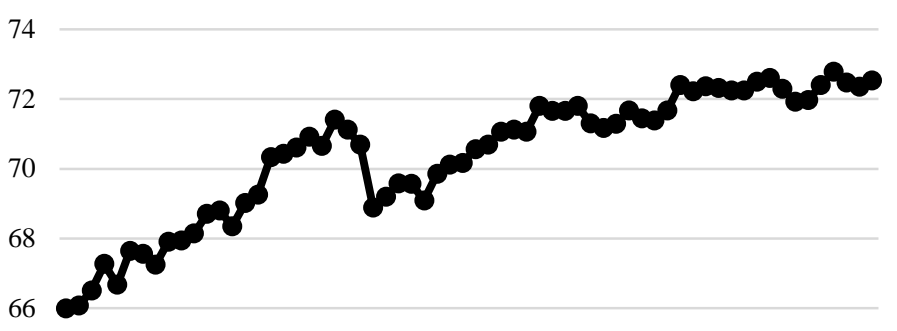

64

62

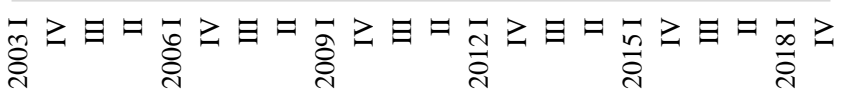

Fig. 2. The number of employed in the RF dynamics (mln ppl.)

Based on the primary data presented, the labor productivity growth rate was calculated:

1) the seasonally adjusted real GDP index is divided by the number of employees and multiplied by 1000 (otherwise the numbers are too small for scaling);

2) the obtained indicator logarithm is calculated and we take its first difference;

3) the indicator obtained in the previous step is multiplied by 4 (to go from the quarterly index to the annual one) and multiplied by 100 (to measure the index in \%).

The dynamics of the obtained indicator is shown in Fig. 3. This time series was used for further analysis.

Both series used in the analysis were tested for stationarity using the ADF test, in both cases the alternative stationarity hypothesis was accepted.

The identification of structural changes in Russia is based on the approach outlined in Bruce Hansen's work [2] on identifying structural changes in labor productivity in the United States.

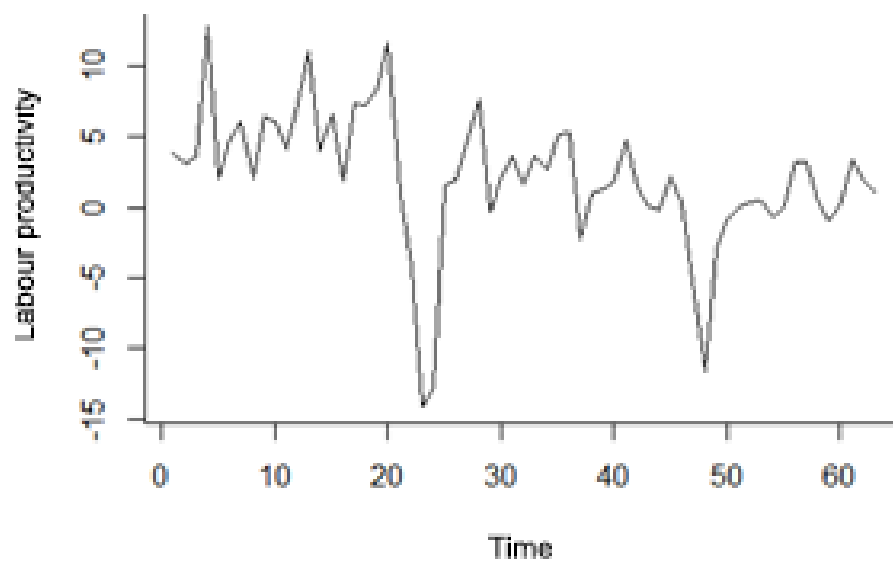

Fig. 3. Dynamics of the rate of growth of labor productivity in the Russian Federation

\section{RESULTS AND DISCUSSION}

1. Labor productivity in Russia: the level and dynamics analysis (1993-2017)

An empirical analysis of the labor productivity in Russia was carried out in two stages.

At the first stage, a cross-country comparison of the labor productivity level (according to the OECD data) was carried out. The analysis focuses on the comparison of labor productivity in Russia and the United States.

In accordance with previous studies [6], it was established that the extensiveness of labor in Russia is much higher than the extensiveness of an employee's labor per year in the OECD countries and the United States (Fig. 4).

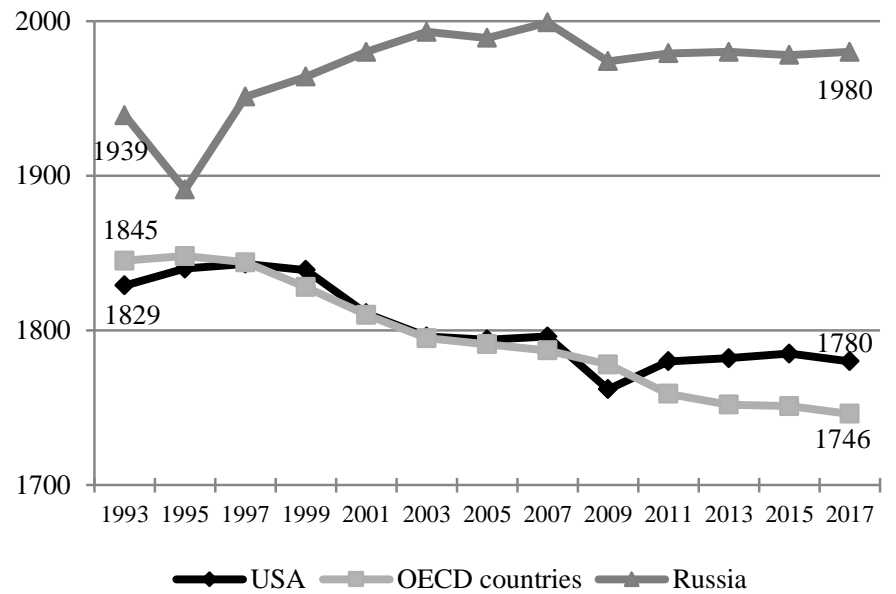

Fig. 4. Comparison of average annual working hours per employee in the Russia, USA and OECD countries

Every year, the gap in labor intensity between the United States, OECD countries and Russia is increasing: from 1993 to 2017, in the United States, the working hours per employee decreased by 49 hours per year, in OECD countries - by 99 hours, whereas in the Russian Federation, it increased by 41 hours. As a result, the average annual time fund of a Russian worker in 2017 was by 200 hours higher than that in the United States.

"Wave-like" dynamics of labor productivity in Russia for the period 1993-2017 is due to the specificity of the mechanisms for adjusting the domestic labor market. During a 
crisis (for example, in 1998-1999 and 2008-2009), productivity falls due to the weak use of the "quantitative" adjustment mechanism in the Russian labor market (employment remains amid a relative decline in wages).

2. Identification of structural changes in labor productivity based on data from Russia (2003-2018)

To assess the presence of a structural change, let us plot the dependence of the test statistics in the Chow test on the shear moment used (Fig. 5).

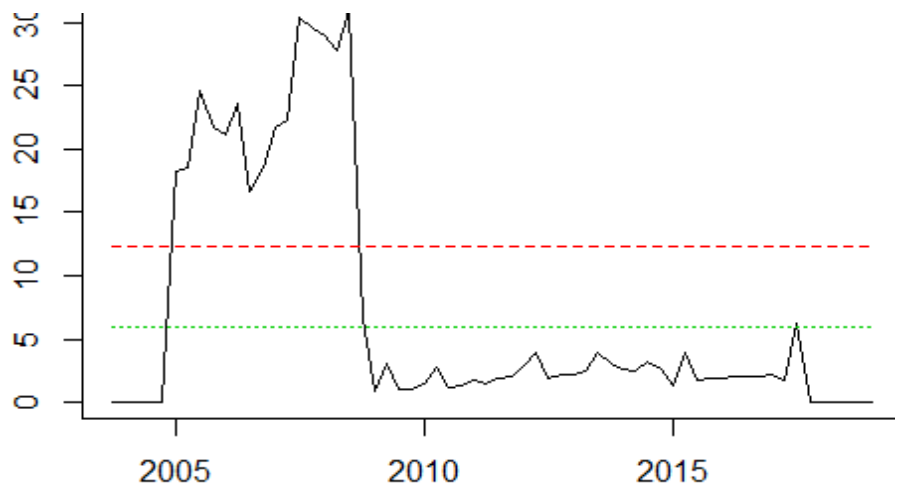

Fig. 5. Structural changes testing

The maximum value of the test statistic exceeds the critical one; therefore, the hypothesis of a structural change presence in the period under consideration is accepted. To assess the shear moment, a graph of the dependence of the residual sum of squares on the shear moment was built (Fig. 6).

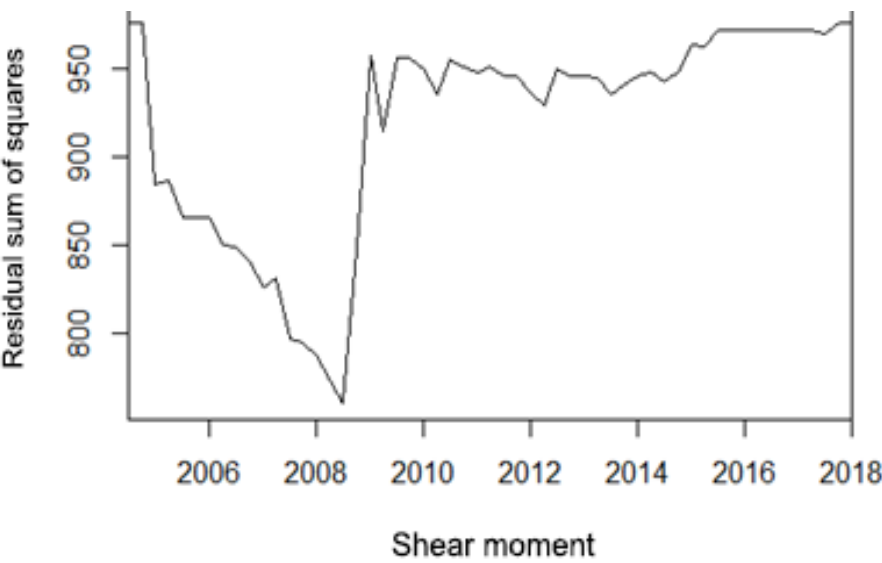

Fig. 6. Dependence of the residual sum of squares on the shear moment

As it can be seen in Figure 6, the residual sum of squares reaches its minimum in the second quarter of 2008, so this moment should be considered a point estimate of the shear moment. The confidence interval for the shear moment turned out to be equal to [2007.75, 2010.50].

To search for other possible moments of structural changes, we divide the original sample into two subsamples by the shear point (2008.50) and perform the same steps in each of the subsamples.

The results of testing for the presence of a structural change in the left subsample are shown in Figure 7.

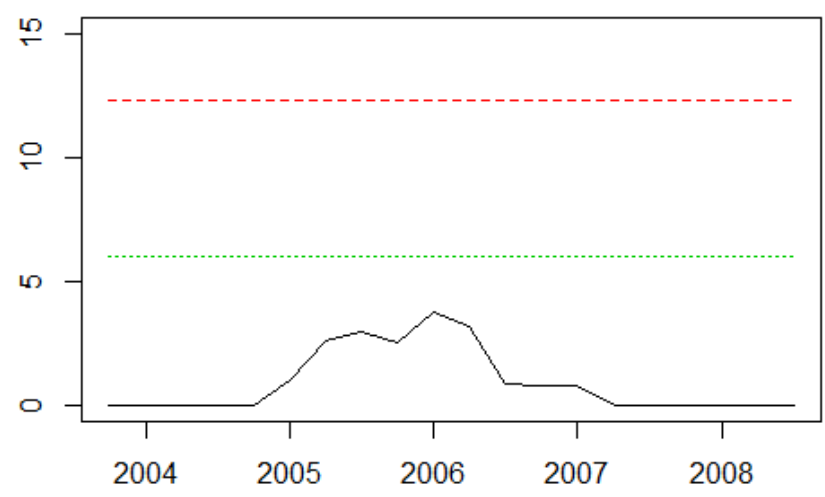

Fig. 7. Results of testing for the presence of a structural change in the left subsample

The results of testing for the presence of a structural change in the right subsample are shown in Figure 8.

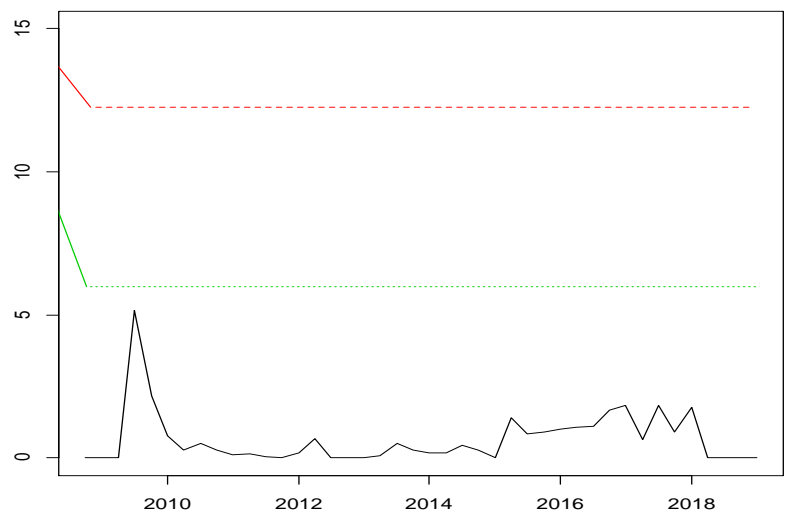

Fig. 8. Results of testing for the presence of a structural change in the right subsample

As can be seen in Fig. 7-8, in both the left and right subsamples, the test statistic values are less than the critical one, therefore, the hypothesis of a structural change absence in both subsamples is not rejected. Consequently, in the considered period there was one structural change, the point estimate of the shear moment is 2008.5.

Let us estimate the AR (1) model parameters separately for the periods 2003-2008 and 2008-2018. The evaluation results are shown in Tables I and II, respectively.

Test statistics for comparing $\mu$ in the periods 2003-2008 and 2008-2018 turned out to be equal to $t=4.12$. Consequently, a change in the labor productivity trend took place approximately in 2008. In the first of the periods considered, the growth rate in labor productivity is much higher than in the last: $5.96 \%$ on average per year in 2003 2008 and $0.27 \%$ in the $2008-2018$ period.

TABLE I. ESTIMATION OF AR (1) PARAMETERS FOR THE 2003-2008 PERIOD

\begin{tabular}{|c|c|c|}
\hline Parameter & Estimation & Standard error \\
\hline$\rho$ & -0.2863 & 0,1843 \\
\hline$\alpha$ & 7.6566 & 1.2387 \\
\hline$\mu$ & 5.9526 & 0.5432 \\
\hline
\end{tabular}


TABLE II. ESTIMATION OF AR (1) PARAMETERS FOR THE 2008-2018 PERIOD

\begin{tabular}{|c|c|c|}
\hline Parameter & Estimation & Standard error \\
\hline$\rho$ & 0.5537 & 0.2053 \\
\hline$\alpha$ & 0.1219 & 0.5948 \\
\hline$\mu$ & 0.2732 & 1.2649 \\
\hline
\end{tabular}

\section{CONCLUSION}

The paper discusses ways to identify structural changes in time series. Testing methods for the presence of a structural change, obtaining point and interval estimates of shear moments are described.

Russian labor productivity dynamics for the 1992-2017 period is due to the specificity of the mechanisms for adjusting the domestic labor market. During the crisis (for example, in 1998-1999 and 2008-2009), productivity falls due to the weak use of the "quantitative" adjustment mechanism in the Russian labor market (preservation of employment against the background of a relative reduction in wages).

On the basis of the data on the labor productivity dynamics in the Russian Federation, the moments of structural changes in the labor productivity dynamics have been estimated. During the period from 2003 to 2018, one structural change was revealed in the Russian economy (the point estimate of the shear moment is the 2nd quarter of 2008). This structural change is characterized by significant negative changes in the labor productivity trend: during the period from 2003 to 2008 , labor productivity grew much faster than in the 2008-2018 period. This is probably due to the external shocks negative impact on the Russian economy (the global financial crisis of 2008-2009 and economic sanctions imposed on Russia by a number of states in connection with the events in Ukraine in 2014).

At the same time, this work has a number of objective limitations which determine promising directions for future research: clarification of the moments of occurring structural changes in labor productivity in Russia (extension of the analysis time horizon) and identification of the structural changes causes (for example, changes in the economy sectoral structure, etc.).

\section{ACKNOWLEDGMENTS}

The reported study was funded by RFBR and BRFBR, project number 20-51-000023.

\section{REFERENCES}

[1] A. Orphanides, "The quest for prosperity without inflation", Journal of Monetary Economics, 2003, vol. 50, pp. 633-663.
[2] B.E. Hansen, "The new econometrics of structural change: dating breaks in U.S. Labor Productivity", Journal of Economic Perspectives, 2001, vol. 15(4), pp. 117-128.

[3] L. Benati, "Drift and breaks in labor productivity", Journal of economic dynamics \& control, 2007, vol. 31, pp. 2847-2877.

[4] R.I. Kapelyushnikov, "Productivity and wages. A little simple arithmetic" [Proizvoditel'nost' i oplata truda. Nemnogo prostoy arifmetiki], Problems of Economics, 2014, vol. 3, pp. 36-61. (In Russ.).

[5] A.A. Zaitsev, Cross-country analysis of sectoral labor productivity in 1991-2008 [Mezhstranovoy analiz otraslevoy proizvoditel'nosti truda v 1991-2008 godakh], Moscow: RAS Institute of Economics, 2014. (In Russ.).

[6] V.E. Kireev, "Productivity, Profitability and Labor Intensity. Russia and OECD countries" [Proizvoditel'nost', dokhodnost' i intensivnost' truda. Rossiya i strany OESR], UrFU Bulletin, 2017, vol. 16(2), pp. 308-326. (In Russ.).

[7] E.V. Lyadova, "Analysis of labor productivity dynamics in Russia: macroeconomic aspect" [Analiz dinamiki proizvoditel'nosti truda v Rossii: makroekonomicheskiy aspekt], Bulletin of N.I. Lobachevsky Nizhny Novgorod University, 2017, vol. 1(45), pp. 46-53. (In Russ.).

[8] I.B. Voskoboinikov, and V.E. Gimpelson, "Labor productivity growth, structural changes and informal employment in the Russian economy" [Rost proizvoditel'nosti truda, strukturnyye sdvigi i neformal'naya zanyatost' v rossiyskoy ekonomike], Problems of Economics, 2015, vol. 11, pp. 30-61. (In Russ.).

[9] I.B. Voskoboynikov, V.E. Gimpelson, Reallocation of labor and productivity growth. Mobility and stability in the Russian labor market \{Reallokatsiya truda i rost proizvoditel'nosti. Mobil'nost' i stabil'nost' na rossiyskom rynke truda], in: V.E. Gimpelson, R. I. Kapelyushnikov (Ed.), Moscow: House of the Higher School of Economics, 2017. (In Russ.).

[10] N.N. Mikheeva, "Regional aspects of the study of labor productivity dynamics" [Regional'nyye aspekty issledovaniya dinamiki proizvoditel'nosti truda], Region. Economics and Sociology, 2014, vol. 1, pp. 6-28. (In Russ.).

[11] N.N. Mikheeva, "Comparative analysis of labuor productivity in Russian regions" [Sravnitel'nyy analiz proizvoditel'nosti truda v rossiyskikh regionakh], Region. Economics and Sociology, 2015, vol. 2, pp. 86-112. (In Russ.).

[12] R. Quandt, "Test of the Hypothesis that a Linear Regression Obeys Two Separate Regimes", Journal of the American Statistical Association, 1960, vol. 55, pp. 324-330. DOI: https://doi.org/10.1080/01621459.1960.10482067

[13] D. W. K. Andrews, "Tests for Parameter Instability and Structural Change With Unknown Change Point", Econometrica, 1993, vol. 61(4), pp. 821-856. DOI: $10.2307 / 2951764$.

[14] D.W.K. Andrews, and W. Ploberger, "Optimal Tests When a Nuisance Parameter Is Present Only under the Alternative", Econometrica, 1994 vol. 62(6), pp. 1383-1414.

[15] B.E. Hansen, "Approximate Asymptotic P Values for Structural-Change Tests", Journal of Business \& Economic Statistics, 1997, vol. 15(1), pp. 60-67.

[16] J. Bai, and P. Perron, "Estimating and Testing Linear Models with Multiple Structural Changes", Econometrica, 1998, vol. 66(1), pp. 47 78. DOI: $10.2307 / 2998540$

[17] J. Bai, "Least squares estimation of a shift in linear process", Journal of Time Series Analysis, 1994, vol. 15(5), pp. 453-472.

[18] J. Bai, "Estimation of a Change Point In Multiple Regression Models", The Review of Economics and Statistics, 1997, vol. 79(4), pp. 551-563. 